This is the author's final, peer-reviewed manuscript as accepted for publication. The publisher-formatted version may be available through the publisher's web site or your institution's library.

\title{
Adsorbate-induced structural changes in 1-3 nm platinum nanoparticles
}

Yu Lei, Haiyan Zhao, Rosa Diaz Rivas, Sungsik Lee, Bin Liu, Junling Lu, Eric Stach, Randall E. Winans, Karena W. Chapman, Jeffrey P. Greeley, Jeffrey T. Miller, Peter J. Chupas, and Jeffrey W. Elam

\section{How to cite this manuscript}

If you make reference to this version of the manuscript, use the following information:

Lei, Y., Zhao, H., Rivas, R. D., Lee, S., Liu, B., Lu, J., ... Elam, J. W. (2014). Adsorbateinduced structural changes in 1-3 nm platinum nanoparticles. Retrieved from http://krex.ksu.edu

\section{Published Version Information}

Citation: Lei, Y., Zhao, H., Rivas, R. D., Lee, S., Liu, B., Lu, J., ... Elam, J. W. (2014). Adsorbate-induced structural changes in 1-3 nm platinum nanoparticles. Journal of the American Chemical Society, 136(26), 9320-9326.

Copyright: Copyright (c) 2014 American Chemical Society

Digital Object Identifier (DOI): doi:10.1021/ja4126998

Publisher's Link: http://pubs.acs.org/doi/abs/10.1021/ja4126998

This item was retrieved from the K-State Research Exchange (K-REx), the institutional repository of Kansas State University. K-REx is available at http://krex.ksu.edu 


\title{
Adsorbate-Induced Structural Changes in 1-3 nm Platinum Nanoparticles.
}

\author{
Yu Lei ${ }^{1,2, \neq}$, Haiyan Zhao ${ }^{3, \neq}$, Rosa Diaz Rivas ${ }^{4}$, Sungsik Lee ${ }^{3}$, Bin Liu ${ }^{5}$, Junling Lu ${ }^{1}$, Eric Stach ${ }^{4}$, Ran- \\ dall E. Winans ${ }^{3}$, Karena W. Chapman ${ }^{3}$, Jeffrey P. Greeley ${ }^{6}$, Jeffrey T. Miller ${ }^{7}$, Peter J. Chupas ${ }^{3}$, and \\ Jeffrey W. Elam ${ }^{1, *}$
}

${ }^{1}$ Energy Systems Division, ${ }^{3} \mathrm{X}$-ray Science Division, ${ }^{7}$ Chemical Sciences and Engineering Division, Argonne National Laboratory, Lemont, IL 60439, United States

${ }^{2}$ Department of Chemical and Materials Engineering, University of Alabama in Huntsville, Huntsville, AL 35899, United States

${ }^{4}$ Center for Functional Nanomaterials, Brookhaven National Laboratory, Upton, NY 11973, United States

${ }^{5}$ Department of Chemical Engineering, Kansas State University, Manhattan, KS 66506, United States

${ }^{6}$ Department of Chemical Engineering, Purdue University, West Lafayette, IN 47907, United States

KEYWORDS platinum nanoparticles, heterogeneous catalyst, X-ray absorption spectroscopy, pair distribution function, bond distance, contraction, ligands

\begin{abstract}
We investigated changes in the Pt-Pt bond distance, particle size, crystallinity, and coordination of Pt nanoparticles as a function of particle size $(1-3 \mathrm{~nm})$ and adsorbate $\left(\mathrm{H}_{2}, \mathrm{CO}\right)$ using synchrotron radiation pair distribution function (PDF) and X-ray absorption spectroscopy (XAS) measurements. The $\sim 1 \mathrm{~nm}$ Pt nanoparticles showed a Pt-Pt bond distance contraction of $\sim 1.4 \%$. The adsorption of $\mathrm{H}_{2}$ and $\mathrm{CO}$ at room temperature relaxed the Pt-Pt bond distance contraction to a value close to that of bulk fcc Pt. The adsorption of $\mathrm{H}_{2}$ improved the crystallinity of the small Pt nanoparticles. However, $\mathrm{CO}$ adsorption generated a more disordered fcc structure for the 1-3 $\mathrm{nm}$ Pt nanoparticles compared to the $\mathrm{H}_{2}$ adsorption Pt nanoparticles. In situ XANES measurements revealed that this disorder results from the electron back donation of the Pt nanoparticles to CO, leading to a higher degree of rehybridization of the metal orbitals in the Ptadsorbate system.
\end{abstract}

\section{INTRODUCTION}

Metal nanoparticles can exhibit dramatically different chemical and physical properties compared to their bulk counterparts. ${ }^{1-4}$ Owing to their highly under-coordinated surfaces, small metal nanoparticles in the sub-10 nm range play an important role in industrial heterogeneous catalysis. $^{5-7}$ The structure of the supported metal nanoparticles can change dynamically under reaction condition such as when molecules adsorb on the surface. A fundamental understanding of the structure of supported, sub$10 \mathrm{~nm}$ metal nanoparticles, under reaction conditions, is an important step towards achieving precise structurereactivity relationship in heterogeneous catalysis and will ultimately lead to better catalysts.

Prominent features of sub-10 nm diameter metal nanoparticles, include a contracted lattice parameter and higher structural disorder with decreasing particle size. Lennard-Jones first predicted that a small contraction (5$6 \%$ ) may occur in the surface layer of a crystal due to surface-tension in $1928 .{ }^{8}$ In the 1930s, scientists found discrepancies between the lattice constants of zinc oxide and alkali halides obtained by electron diffraction and X-ray diffraction, respectively. Bunn suggested that these differences were due to a change in the lattice constants of zinc oxide at the surface, since electron diffraction was more surface sensitive than X-ray diffraction. ${ }^{9}$ Finch and Fordham found that some small alkali halide crystals had larger lattice constants than their bulk counterparts. ${ }^{10}$ Since then, debate over the origin of lattice contraction and expansion has persistent. In the 1950s, the debate was eventually settled when lattice contraction in small particles was determined in alkali halides and metals. ${ }^{11-12}$ This contraction increased with decreasing particle size for particles below $10 \mathrm{~nm}$ in diameter." It was also realized that the structure and shape of very small particles may not be the same as their bulk counterparts, ${ }^{12}$ which could lead to incorrect interpretations of diffraction results. Consequently, an advanced technique is desired to provide bond-length information independent of materials crystal structure.

With the development of X-ray absorption spectroscopy (XAS) in the 1970s, it was discovered that the nearestneighbor bond distance decreased with decreasing particle size for $\mathrm{Cu}$ and $\mathrm{Ni}$ using extended X-ray absorption fine structure (EXAFS). ${ }^{13} \mathrm{~A}$ similar trend was also found 
for supported precious metal nanoparticles. ${ }^{14-15}$ A 5\% contraction was observed for supported, $1 \mathrm{~nm} \mathrm{Au}$ and Pt nanoparticles independent of the supports.

However, Norskov and coworkers cast doubt on the EXAFS measurement at room temperature after calculating the pair distribution function (PDF) of $\mathrm{Cu}$ clusters with 100-1000 atoms using molecular-dynamics simulations. They suggested that the observed lattice contraction was due to anharmonic vibrations of the surface atoms at room temperature. ${ }^{16}$ More recently, van Bokhoven and coworkers performed in situ EXAFS on supported Pt nanoparticles between $77 \mathrm{~K}$ and $673 \mathrm{~K}$. Accurate fittings were obtained for their EXAFS spectra at elevating temperature by including the third and fourth cumulants in the amplitude and phase of the EXAFS functions, where changes in the Debye-Waller factor due to asymmetry and sharpening or broadening of the PDF were considered. ${ }^{17}$ However, including the third and fourth cumulants could also easily lead to overfitting-that is, applying too many variables.

In recent years, the synchrotron X-ray PDF has emerged as an important tool to investigate supported catalysts at the atomic scale. ${ }^{18-19}$ Unlike EXAFS data analysis which is limited to the first few neighbor shells, PDF provides quantitative structural information on both the short- and long-range order of small nanoparticles. ${ }^{20-21}$ The PDF, $G(r)$, can be obtained by Fourier transforming the normalized scattering function, $S(Q)$, so that no intensive data fitting is required.

In this work, we combined PDF and XAS measurements to reveal the lattice contraction and expansion of supported small platinum nanoparticles as a function of the particle size and the adsorbate. Our previous X-ray absorption near edge structure (XANES) study on Pt nanoparticles supported on different surfaces showed that the support effects with respect to lattice constants were minimal at constant Pt nanoparticle size. ${ }^{15}$ Thus, in this work, we focused on 1-3 nm Pt nanoparticles supported on spherical alumina $\left(\mathrm{Al}_{2} \mathrm{O}_{3}\right.$, Alfa-Aesar NanoDur $\left.{ }^{\mathrm{TM}}\right)$. This spherical alumina support facilitates transmission electron microscopy (TEM) measurements.

\section{EXPERIMENTAL DETAILS}

Preparation of 1-3 nm Pt Nanoparticles. Supported platinum nanoparticles were prepared by atomic layer deposition (ALD). All the Pt samples were prepared in a continuous-flow stainless steel reactor operated under a base pressure of $\sim 1$ Torr. $^{22}$ Spherical alumina nanopowder (NanoDur ${ }^{\mathrm{TM}} \mathrm{sp}-\mathrm{Al}_{2} \mathrm{O}_{3}$, Alfa-Aesar) with a typical particle diameter of $40-50 \mathrm{~nm}$ and surface area of $32-40 \mathrm{~m}^{2} / \mathrm{g}$ were used as the support material. Five hundred milligrams of sp- $\mathrm{Al}_{2} \mathrm{O}_{3}$ were evenly spread into a flat stainless steel tray and loaded into the ALD reactor. Before performing the Pt ALD, the sp- $\mathrm{Al}_{2} \mathrm{O}_{3}$ was first cleaned in situ using 400 sccm $10 \%$ ozone at $523 \mathrm{~K}$. Pt ALD was performed using Trimethyl (methylcyclopentadienyl) platinum (IV) (Pt(MeCp) $\mathrm{Me}_{3}$, Sigma-Aldrich) and oxygen. Three samples were prepared using 1, 3, and 5 Pt ALD cycles over sp-
$\mathrm{Al}_{2} \mathrm{O}_{3}$, written as $1 \mathrm{c} \mathrm{Pt} / \mathrm{sp}-\mathrm{Al}_{2} \mathrm{O}_{3}, 3 \mathrm{C} \mathrm{Pt} / \mathrm{sp}-\mathrm{Al}_{2} \mathrm{O}_{3}$ and ${ }_{5} \mathrm{C}$ $\mathrm{Pt} / \mathrm{sp}-\mathrm{Al}_{2} \mathrm{O}_{3}$, respectively.

Characterization. An Aberration-Corrected Transmission Electron Microscope, FEI Titan $80-300 k V$ was used for imaging. High Resolution TEM images were acquired at $300 \mathrm{kV}$ with a base pressure of $5 \times 10^{-7}$ Torr at room temperature using a Gatan UltraScan CCD Camera. Pt metal loadings were determined by X-ray fluorescence spectroscopy (XRF, Oxford ED20oo) and inductively coupled plasma (ICP, Varian Vista-MPX instrument) measurements.

Pair Distribution Function. Scattering data of PDF were collected at beamline 11-ID-B at the Advanced Photon Source (APS) at Argonne National Laboratory (ANL). High energy $\mathrm{X}$-rays $(58 \mathrm{keV}, \lambda=0.2127 \AA)$ were used in combination with a large amorphous silicon-based area detector. The Pt catalyst was loaded into a Kapton capillary as a flow cell which allowed the flow of reactant gases during the in situ PDF measurements. ${ }^{23}$ Temperature was precisely controlled by a cryosystem (Oxford, Cryostream 700 Plus). The as-prepared $\mathrm{Pt}$ catalysts (Pt-in-air) were first reduced in $3.5 \% \mathrm{H}_{2} / \mathrm{He}$ at $500 \mathrm{~K}$ for $30 \mathrm{~min}$. Then ultrahigh purity (UHP) He was used to purge the catalyst for $30 \mathrm{~min}$ at $500 \mathrm{~K}$ to generate the ligand-free Pt surface (Pt-in-He). The Pt sample was then cooled in UHP He to $300 \mathrm{~K}$ and subsequently exposed to $3.5 \% \mathrm{H}_{2} / \mathrm{He}$ for hydrogen adsorption (Pt-in- $\left.\mathrm{H}_{2}\right)$. The $\mathrm{Pt}$ sample then was again flashed to $500 \mathrm{~K}$ at $6 \mathrm{~K} / \mathrm{min}$ and cooled in UHP He. Finally, the sample was exposed to $5 \% \mathrm{CO} / \mathrm{He}$ for $\mathrm{CO}$ adsorption (Pt-in-CO). PDF measurements were collected continuousy during the entire sample treatment.

The 2-D scattering images were integrated to obtain 1-D scattering intensity data using software Fit2D. ${ }^{24}$ The structure function $S(Q)$ was obtained within software PDFgetX2. ${ }^{25}$ Direct Fourier transform of the reduced structure function $F(Q)=Q[S(Q)-1]$ led to the reduced pair distribution function, $G(r)$, with $\mathrm{Q}_{\max }=23 \AA^{-1}$. Contributions from the sp- $\mathrm{Al}_{2} \mathrm{O}_{3}$ support were measured from room temperature to $500 \mathrm{~K}$ and subtracted to yield differential PDF ( $d$-PDF). The $d$-PDF data will show contributions only from Pt-atom correlations.

X-ray Absorption Spectroscopy (XAS). X-ray absorption spectroscopy measurements at the $\mathrm{Pt} \mathrm{L}_{3}$ edge $(\sim 11.56$ $\mathrm{keV}$ ), including extended X-ray absorption fine structure spectroscopy (EXAFS) and X-ray absorption near edge structure spectroscopy (XANES), were performed at the bending-magnet beamline (10-BM) of the Materials Research Collaborative Access Team (MR-CAT) at the APS at ANL. XAS data was collected in the transmission mode. Pt nanoparticle samples were treated identically as that used in the in situ PDF experiments described above.

EXAFS data fittings were performed using WinXAS (version 3.1). Reference phase and amplitude files for PtPt were obtained from the Pt foil EXAFS spectrum. A single shell model fit of the forward and inverse $\mathrm{k}^{2}$-weighted EXAFS data was obtained between $\mathrm{k}=2.9-11.0 \AA^{-1}$ and $\mathrm{r}=$ 1.3 - 3.0 $\AA$, respectively. Data quality was checked by performing $\mathrm{k}^{1}$ - and $\mathrm{k}^{3}$-weighted EXAFS fittings with the same parameters. 
Small Angle X-ray Scattering (SAXS). SAXS experiments were performed at the APS 12ID-B station. The Pt catalyst samples were loaded into 1.5-mm diameter quartz capillary tubes for the SAXS measurements. The $2 \mathrm{D}$ SAXS data were collected on the Pilatus $2 \mathrm{M}$ area detector (DECTRIS Ltd.), a q range of $0.006-0.7 \AA^{-1}$ with an incident energy of $12 \mathrm{keV}$. The scattering vector, $\mathrm{Q}$, was calibrated using a silver behenate. Quantitative data analyses were performed using spherical form factors with a maximum entropy algorithm using the Irena package. ${ }^{26}$

Classical Molecular Dynamics (MD) Simulations. The MD simulations were performed using the DL_POLY 2.20 package. ${ }^{27}$ The $\mathrm{Al}-\mathrm{Al}, \mathrm{O}-\mathrm{O}, \mathrm{Al}-\mathrm{O}$ interactions within the alumina slab were described using the Buckingham pair-potential, using the parameters provided by Matsui et al. ${ }^{28}$ The Pt-Pt interactions were treated with the Sutton-Chen potential. ${ }^{29-30}$ The Pt-Al and Pt-O interactions between metal and the substrate were treated with the Lennard-Jones potential (see Table S2 in SI). ${ }^{31-32}$

The alumina support was modeled using a stoichiometric $\alpha-\mathrm{Al}_{2} \mathrm{O}_{3}$ slab with the (oo1) surface. The slab consists of 6 layers, with 1080 atoms. The entire system is maintained charge neutral. The dimensions of the alumina slab are $24.85 \AA \times 28.69 \AA \times 50.00 \AA$, and is periodically bounded. The consecutive surfaces are separated by a vacuum spacing equivalent to a thickness of 12 layers.

To calculate the PDFs of both supported and unsupported Pt nanoparticles, the simulations were carried out in microcanonical ensembles. The cutoff radius for both short-range forces and the van der Waals forces was selected to be 12.3. The Ewald sum for electrostatic interactions was used and the precision is set to be $1 \times 10^{-6}$. The velocity-Verlet integration algorithm was used for time propagation with a time step of 1 fs. All the simulations were initially equilibrated at $500 \mathrm{~K}$ for $100 \mathrm{ps}$. The PDFs were averaged based on the last 50,000 configurations. All the atoms are allowed to relax during the simulation.

\section{RESULTS AND DISCUSSION}

Studies of small changes in bond distance require highly-dispersed and ligand-free supported Pt nanoparticles with narrow size distribution. Atomic layer deposition has proved effective in preparing well-dispersed, precious metal nanoparticles on high surface area supports using sequential, self-limiting surface reactions. ${ }^{33-34}$ We used alternating exposures to $\mathrm{Pt}(\mathrm{MeCp}) \mathrm{Me}_{3}$ and oxygen at 523 $\mathrm{K}$ to prepare supported ALD Pt nanoparticles. One, three, and five Pt ALD cycles were performed on spherical alumina $\left(\mathrm{Al}_{2} \mathrm{O}_{3}\right)$ in a continuous-flow, stainless steel reactor operated under a base pressure of $\sim 1$ Torr ultra-high purity nitrogen carrier gas. ${ }^{22}$ The $\mathrm{Pt}$ for the $1 \mathrm{c}, 3 \mathrm{C}$ and $5 \mathrm{C}$ samples were $1.4 \mathrm{wt} \%, 8.7 \mathrm{wt} \%$ and $16 \mathrm{wt} \%$, respectively, as determined by X-ray fluorescence spectroscopy (XRF). These loadings are lower than those obtained previously at $573 \mathrm{~K}$ (2.5 wt\% for 1c Pt and $10.4 \mathrm{wt} \%$ for $3 \mathrm{C} \mathrm{Pt}$ ). ${ }^{35-36}$ This change is expected given that the ALD Pt growth per cycle decreases with decreasing temperature. ${ }^{37}$ We selected the $523 \mathrm{~K}$ deposition temperature because it produced smaller particles with a narrower size distribution.
We determined the Pt nanoparticle size using TEM, small angle X-ray scattering (SAXS), and PDF, (Table 1) and found consistent results among the three techniques.

Table 1. Platinum metal loading and particle size determined by various methods.

\begin{tabular}{|c|c|c|c|c|}
\hline & \begin{tabular}{|c|} 
Pt Loading \\
wt $\%$
\end{tabular} & $\mid \underset{n \mathrm{nt}^{\mathrm{b}}}{\mathrm{d}_{\mathrm{bt}}(\mathrm{TEM})}$ & $\mid \begin{array}{l}\mathrm{d}_{\mathrm{Pt}}(\mathrm{SAXS}) \\
\mathrm{nm}^{\mathrm{c}}\end{array}$ & $\mathrm{nm}^{\mathrm{d}} \mathrm{d}_{\mathrm{Pt}_{\mathrm{t}}}(\mathrm{PDF})$ \\
\hline 1c $\mathrm{Pt}$ & 1.4 & $1 \pm 0.3$ & 1.2 & 1.2 \\
\hline $3 \mathrm{cPt}$ & 8.7 & $2 \pm 0.5$ & 2.2 & 2.4 \\
\hline $5 \mathrm{c} \mathrm{Pt}$ & 16.0 & $3 \pm 0.6$ & 3.2 & 3.4 \\
\hline
\end{tabular}

abtained by XRF and ICP

${ }^{\mathrm{b}}$ obtained by TEM (Figure 1 )

c obtained by small angle X-ray scattering (Figure 2)

${ }^{d}$ obtained by pair distribution function (Figure S2)
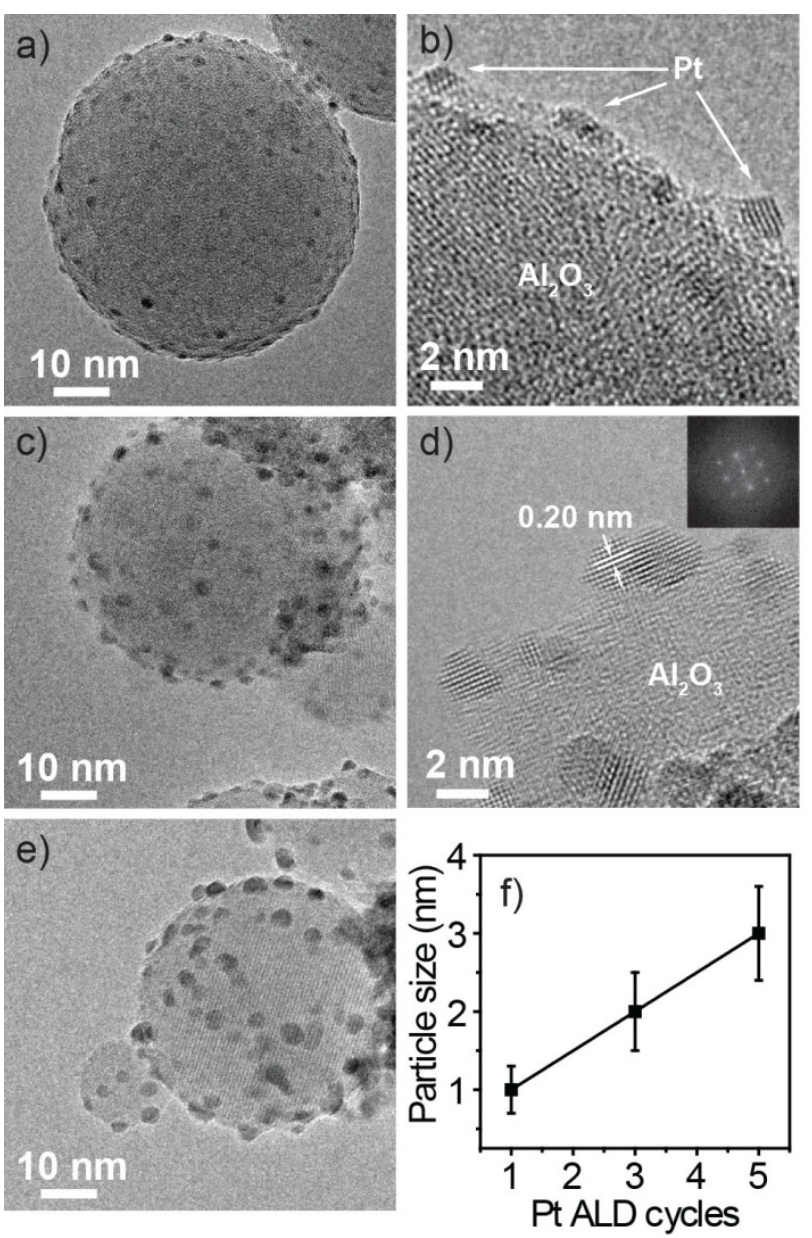

Figure 1. (a) TEM and (b) HR-TEM images of $1 \mathrm{ct} / \mathrm{Al}_{2} \mathrm{O}_{3}$; (c) TEM and (d) HR-TEM images of $3 \mathrm{c} \mathrm{Pt} / \mathrm{Al}_{2} \mathrm{O}_{3}$ with FFT shown in the insert; (e) TEM image of ${ }_{5} \mathrm{C} \mathrm{Pt} / \mathrm{Al}_{2} \mathrm{O}_{3}$; (f) size distribution of Pt nanoparticles.

The Pt nanoparticles were well-dispersed on the $\mathrm{Al}_{2} \mathrm{O}_{3}$ surface (Figure 1 ) with particle size distributions of $1 \pm 0.3$ $\mathrm{nm}, 2 \pm 0.5 \mathrm{~nm}$, and $3 \pm 0.6 \mathrm{~nm}$ for the $1 \mathrm{c}, 3 \mathrm{c}$, and ${ }_{5 \mathrm{c} \mathrm{Pt}}$ samples, respectively. These sizes are smaller than the Pt prepared at $573 \mathrm{~K}$ on the same support. ${ }^{35}$ High resolution TEM (HR-TEM) imaging was used to determine the shape 
and crystallinity of the supported Pt nanoparticles. Figure 1 (b) and (d) show HR-TEM images of the $1 \mathrm{c}$ and $3 \mathrm{c} \mathrm{Pt}$ nanoparticle samples on $\mathrm{Al}_{2} \mathrm{O}_{3}$. The $3 \mathrm{c}$ sample formed truncated octahedra with widths around $2 \mathrm{~nm} \pm 0.5$ and distance between the lattice fringes of $0.2 \mathrm{~nm}$ corresponds to the interplanar distance of $\mathrm{Pt}(100)$.

The Pt particle size was also evaluated using SAXS measurements. Figure 2(a) shows the 1-D scattering curves obtained from 2-D SAXS measurements. The broad features on the curves shifted to higher q values with increasing Pt ALD cycles, consistent with an increase in the Pt particle size. The particle sizes extracted from the SAXS measurements for the as-prepared Pt nanoparticles are $1.2 \mathrm{~nm}, 2.2 \mathrm{~nm}$, and $3.2 \mathrm{~nm}$ for the $1 \mathrm{c}, 3 \mathrm{c}$, and $5 \mathrm{c} \mathrm{Pt}$ samples, respectively.
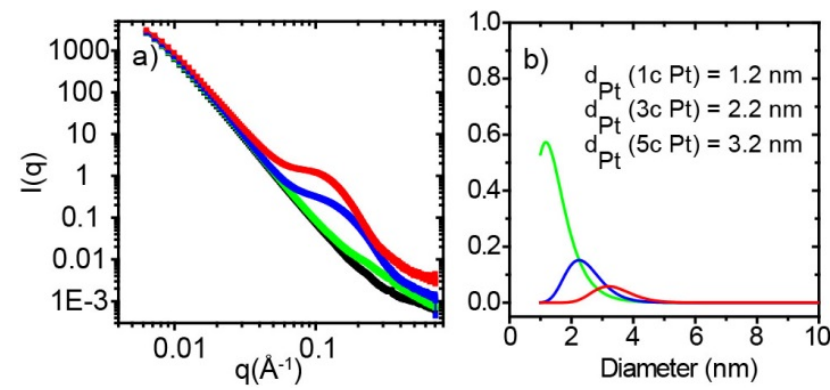

Figure 2. (a) One-dimensional SAXS curves of $\mathrm{Pt} / \mathrm{Al}_{2} \mathrm{O}_{3}$ and bare $\mathrm{Al}_{2} \mathrm{O}_{3}$ resulting from average the $2 \mathrm{D}$ diffraction image; (b) size distribution of the as-prepared Pt nanoparticles obtained from SAXS modeling. Black $\mathrm{Al}_{2} \mathrm{O}_{3}$. Green 1c Pt $/ \mathrm{Al}_{2} \mathrm{O}_{3}$. Blue $3 \mathrm{c} \mathrm{Pt} / \mathrm{Al}_{2} \mathrm{O}_{3}$. Red ${ }_{5 \mathrm{c}} \mathrm{Pt} / \mathrm{Al}_{2} \mathrm{O}_{3}$.

Differential PDF (d-PDF) is an analytical technique in which the contribution from the support is subtracted from the total PDF, leaving only the atom-atom correlations from the supported particles. ${ }^{20}$, 38-39 PDF measurements were performed on the $\mathrm{Al}_{2} \mathrm{O}_{3}$ support from $300 \mathrm{~K}$ to $500 \mathrm{~K}$ at $6 \mathrm{~K} / \mathrm{min}$ to serve as a reference for the subsequent $d$-PDFs data analysis. Figure $\mathrm{S}_{1}$ demonstrates that the change in $\mathrm{Al}_{2} \mathrm{O}_{3}$ structure over this temperature range is negligible. After subtracting the $\mathrm{Al}_{2} \mathrm{O}_{3}$ PDF data, the resulting $d$-PDF plots in Figure $3(\mathrm{a})$ and (b) reveal a series of sharp peaks, each reflecting a particular atom-atom correlation (e.g., Pt-Pt and Pt-O). The peaks at around $2.78 \AA$, $3.95 \AA$, and $4.75 \AA$ are characteristic of the Pt fcc structure. These peaks decay to zero faster for smaller Pt particles, reflecting the absence of large-scale correlations in these particles. In particular, there are no features in the $d$-PDF data beyond $\mathrm{r} \approx 1.0 \mathrm{~nm}$ for the $1 \mathrm{c}$ Pt sample, suggesting that there are no particles larger than $\sim 1 \mathrm{~nm}$. As for the $3 \mathrm{c}$ and $5 \mathrm{c}$ Pt samples, the nanoparticle sizes are estimated as $\sim 2 \mathrm{~nm}$ and $\sim 3 \mathrm{~nm}$, respectively.

As PDF uses high energy X-ray ( $58 \mathrm{keV}$ in this work), the effect of beam damage to the samples, i.e., possible sintering of Pt nanoparticles caused by high energy X-ray, was examined prior to the in situ adsorption experiments. The samples were constantly exposed to $58 \mathrm{keV} \mathrm{X}$-ray for two hours at room temperature and PDFs were taken simultaneously. No obvious change of the size of Pt nanoparticles was observed.

For all of the as-prepared samples, there is a small, broad peak at about $2.00 \AA$ corresponding to scattering from the Pt-O pair. This suggests that the as-prepared $\mathrm{Pt}$ nanoparticles are partially oxidized on the surface. Because oxygen is a low $\mathrm{Z}$ element, the scattering from $\mathrm{Pt}-\mathrm{O}$ is relatively weak compared to $\mathrm{Pt}-\mathrm{Pt} .{ }^{40}$ Precise particle size was obtained from quantitative fitting of the $d$-PDF data from the Pt in He using software PDFgui ${ }^{25}$ by applying a fcc Pt structure with spherical shape. As shown in Figure S2, the particle sizes obtained were $1.2 \mathrm{~nm}, 2.4 \mathrm{~nm}$ and $3.4 \mathrm{~nm}$ for $1 \mathrm{c}, 3 \mathrm{c}$ and $5 \mathrm{c} \mathrm{Pt}$, respectively. These values from the $d$-PDF data are consistent with those obtained from TEM and SAXS.

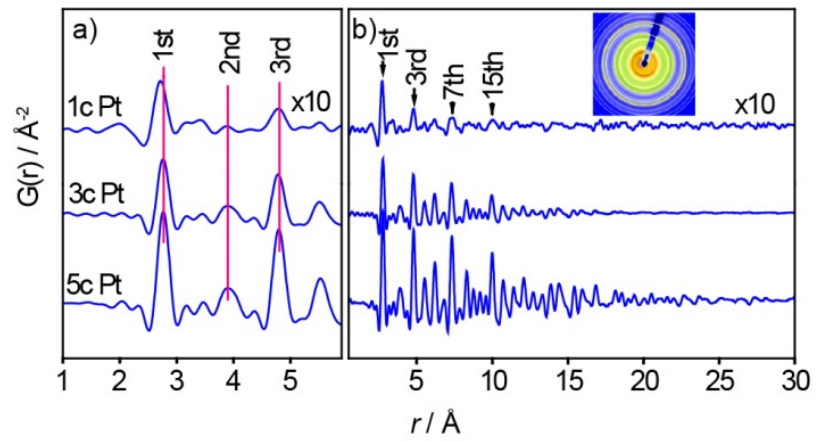

Figure 3. (a) and (b) Differential PDFs for as-prepared 1c $\mathrm{Pt} / \mathrm{Al}_{2} \mathrm{O}_{3}, 3 \mathrm{C} \mathrm{Pt} / \mathrm{Al}_{2} \mathrm{O}_{3}$, and ${ }_{5} \mathrm{C} \mathrm{Pt} / \mathrm{Al}_{2} \mathrm{O}_{3}$ measured under ambient conditions. Resulting from integration of the $2 \mathrm{D}$ diffraction images (representative image shown in the insert).

As mentioned above, it is important to use ligand free Pt nanoparticles to obtain unambiguous results on the effect of adsorbates. However, the as-prepared 1-3 nm Pt nanoparticles were likely partially or fully oxidized during the sample transfer and the gap between sample preparation and analysis. In addition, it was reported that for precious metal nanoparticles in this size regime, degree of oxidation increased with decreasing Pt particle size and increasing in the percentage of surface atoms. ${ }^{41}$ It was indeed the case from XAS measurements on the asprepared Pt nanoparticle samples (Figure S3). The asprepared Pt samples all showed clear Pt-O pair scattering in the R-space of EXAFS spectra. In particular, for $1 \mathrm{C}$ $\mathrm{Pt} / \mathrm{Al}_{2} \mathrm{O}_{3}$ who had the smallest Pt particle size amount all samples, Pt-O is the dominant feature in its EXAFS spectrum. Therefore, in this work, the Pt nanoparticles samples were fully reduced by $\mathrm{H}_{2}$ at $500 \mathrm{~K}$ and protected in He in the in situ sample cell at the beamline prior to the gas molecule adsorption experiments for both PDF and XAS measurements. 


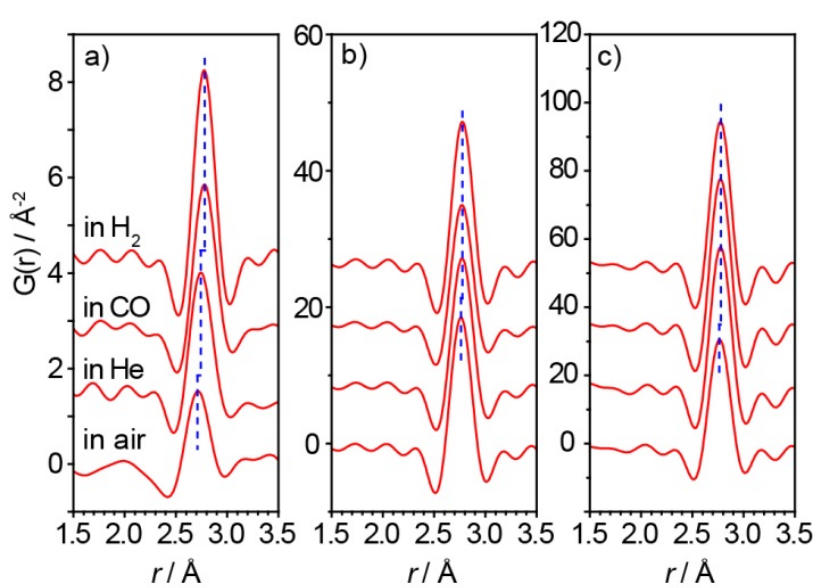

Figure 4. Differential PDFs for (a) ic $\mathrm{Pt} / \mathrm{Al}_{2} \mathrm{O}_{3}$, (b) $3 \mathrm{C}$ $\mathrm{Pt} / \mathrm{Al}_{2} \mathrm{O}_{3}$, and (c) $5 \mathrm{c} \mathrm{Pt} / \mathrm{Al}_{2} \mathrm{O}_{3}$ under different conditions.

Figure 4 shows the d-PDF data measured for the 1c, 3c, and $5 \mathrm{C}$ samples in various states: as-prepared (Pt in air), $\mathrm{H}_{2}$-reduced and protected in $\mathrm{He}$ ( $\mathrm{Pt}$ in $\left.\mathrm{He}\right)$, in $\mathrm{H}_{2}$, and in CO. The literature value for the Pt-Pt bond distance in bulk Pt is $2.78 \AA .{ }^{42}$ As shown in Figure $4(\mathrm{a})$, the asprepared 1c Pt sample has a first shell Pt-Pt bond distance of $2.72 \AA$. The as-prepared Pt was then fully reduced in $3.5 \% \mathrm{H}_{2}$ at $500 \mathrm{~K}$ for 30 minutes. The cell was then evacuated, backfilled with ultrahigh purity helium at $500 \mathrm{~K}$ to completely remove hydrogen from the supported $\mathrm{Pt}$ nanoparticles (Pt-in-He), and cooled to room temperature. The Pt-Pt bond distance of the $\sim 1 \mathrm{~nm}$ Pt-in-He nanoparticles measured at room temperature was $2.74 \AA$, a $\sim 1.4 \%$ contraction with respect to the bulk value. Next, the Ptin-He nanoparticles were exposed to $3.5 \% \mathrm{H}_{2} / \mathrm{He}$ and $5 \%$ $\mathrm{CO} / \mathrm{He}$, respectively, to study the effects of these adsorbates on the Pt-Pt bond distance. Upon adsorption of the $\mathrm{H}_{2}$ and $\mathrm{CO}$, the Pt-Pt bond distance relaxed to $2.77 \AA$ and 2.78 $\AA$, respectively, close to the bulk Pt value. After the adsorption experiments, the supported Pt nanoparticles were re-oxidized by annealing in $5 \% \mathrm{O}_{2} / \mathrm{He}$ at $500 \mathrm{~K}$. The bond distance again contracted to $2.70 \AA$, indicating no sintering of the $\mathrm{Pt}$ nanoparticles during the various treatments. Moreover, the even shorter distance compared to the as-prepared value suggests an even smaller Pt metal core following the $\mathrm{O}_{2}$ treatment than for the asprepared, partially-oxidized Pt particles. As shown in Figure 4 (b) and (c), the PDF measurements for the contraction and relaxation effects on the 2-3 nm Pt nanoparticles are relatively small compared to the $1 \mathrm{~nm}$ sample. For the as-prepared samples, the Pt-Pt bond distance contracted only slightly to $2.77 \AA$. The $2-3 \mathrm{~nm}$ Pt-in-He nanoparticles with and without adsorbates exhibited the bulk Pt-Pt bond distance of $2.78 \AA$.

The contraction and relaxation of the Pt-Pt bond distance can be clearly observed from the outer shell of Pt. The $1^{\text {st }}, 3^{\text {rd }}, 7^{\text {th }}$ and $15^{\text {th }}$ Pt-Pt shells are major peaks in the Pt PDF data, and these distances are summarized in Table $\mathrm{S} 1$ and Figure 5 . The $15^{\text {th }}$ shell, corresponding to a Pt-Pt distance of $\sim 10 \AA$, is similar to the average size of the $1 \mathrm{c} \mathrm{Pt}$ nanoparticles. Consequently, the changes in this Pt-Pt pair can be considered the contraction and expansion of the whole Pt nanoparticle. For the 1c Pt-in-He, this shell shows a slight contraction of $\sim 0.3 \%$ with respect to bulk. Upon $\mathrm{H}_{2}$ adsorption, the particles show a slight expansion $\sim 0.1 \%$ with respect to the bulk. When $\mathrm{CO}$ was adsorbed, the whole $\mathrm{Pt}$ nanoparticles exhibited $\sim 0.3 \%$ expansion with respect to the bulk.
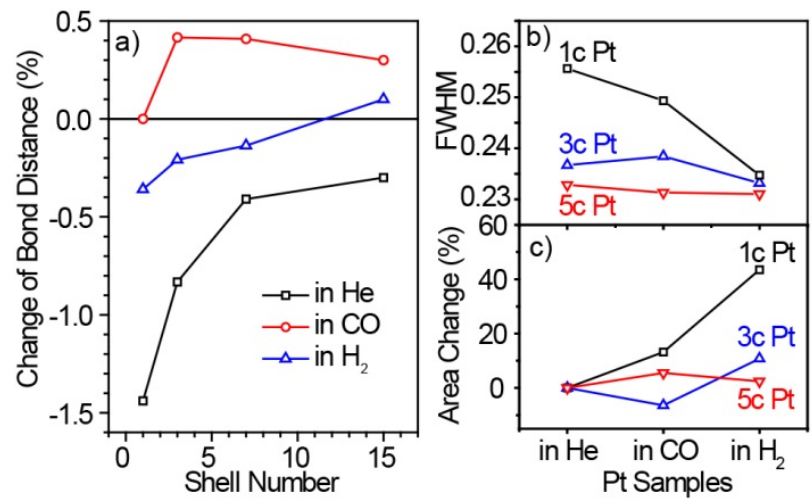

Figure 5. (a) Pt-Pt bond distance expansion and contraction obtained from d-PDFs for $1 \mathrm{c} \mathrm{Pt} / \mathrm{Al}_{2} \mathrm{O}_{3}$ for reduced $\mathrm{Pt}$, with adsorbed $\mathrm{CO}$ and with adsorbed $\mathrm{H}_{2}$, respectively, with respective to $\mathrm{Pt}$ bulk value. (b) full width at half maximum (FWHM) and (c) area of the first Pt-Pt peak at $\sim 2.78 \AA$ expansion and contraction obtained from $d$-PDFs for $\mathrm{Pt}$ in $\mathrm{He}$, with adsorbed $\mathrm{CO}$ and with adsorbed $\mathrm{H}_{2}$, respectively.

The shape and intensity of the peaks in the PDFs directly correlate to the anisotropy of $1-3 \mathrm{~nm}$ Pt nanoparticles. A change induced by adsorbates is the crystallinity in the Pt nanoparticles, which can be described by the full width at half maximum (FWHM) of the Pt-Pt bond distance at $\sim 2.78 \AA{ }^{43}$ In Figure 5(b), the FWHM for the Ptin-He in the order of $1 \mathrm{c} \mathrm{Pt}>3 \mathrm{c} \mathrm{Pt}>{ }^{\mathrm{c}} \mathrm{c}$ Pt. This suggests smaller Pt NPs have a higher degree of disordered nature. The FWHM of Pt-in- $\mathrm{H}_{2}$ is smaller than the Pt-in-He. This indicates that the adsorption of $\mathrm{H}_{2}$ enhances the crystallinity of smaller $\mathrm{Pt}$ nanoparticles. Yang and coworkers also observed similar phenomena using a combination of HR-TEM, EXAFS and density functional theory (DFT) studies. ${ }^{44}$ Surprisingly, CO adsorption would not only lead to larger Pt-Pt bond relaxation but also larger FWHM than $\mathrm{H}_{2}$ adsorption, implying greater disorder of Pt nanoparticles.

It was suggested that the contraction of small Pt nanoparticles was due to under coordination of the surface $\mathrm{Pt}$ atoms. ${ }^{45-46}$ Adsorbates, such as $\mathrm{CO}$ and $\mathrm{H}_{2}$, would increase the coordination of $\mathrm{Pt}$ atoms thereby relaxing the contraction. This hypothesis is indeed supported by our PDF results. The Pt-Pt coordination can be quantified by using the area of the peak at $2.78 \AA$ shown in Figure 5(c). The effect is most significant for the $\sim 1 \mathrm{~nm}$ particles since virtually all of the Pt atoms are at the surface. Upon adsorption of $\mathrm{CO}$ and $\mathrm{H}_{2}$, the $2.78 \AA$ peak area increased by $\sim 13 \%$ and $\sim 44 \%$, respectively. The greater increase in the area of the first-shell of $\mathrm{Pt}-\mathrm{in}-\mathrm{H}_{2}$ than $\mathrm{Pt}$-in-CO without increasing particle size (no change in $\mathrm{r}_{\max }$ ) indicates larger increase in coordination numbers of Pt-Pt in $\mathrm{H}_{2}$ than in $\mathrm{CO}$. In contrast, the changes in peak area for the $3 \mathrm{C}$ and $5 \mathrm{C}$ samples were much smaller in the presence of $\mathrm{CO}$ and $\mathrm{H}_{2}$ 
since most of the Pt atoms in these larger particles are already fully coordinated.

(a)
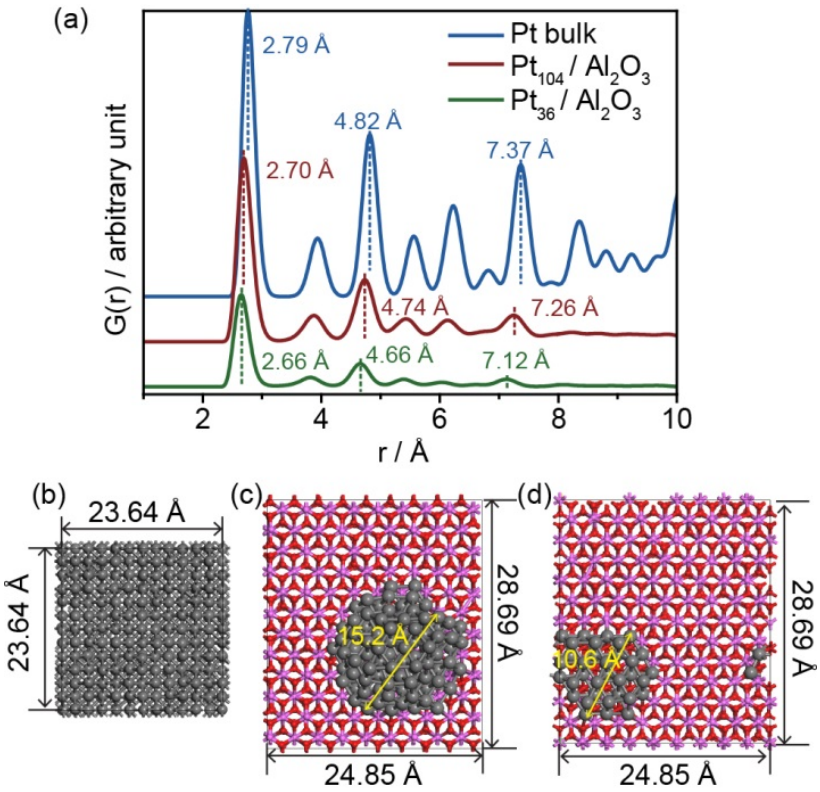

Figure 6. (a) PDFs, G(r), for Pt bulk (blue), $\mathrm{Pt}_{104}$ on substrate (red), and $\mathrm{Pt}_{36}$ on substrate (green), respectively; (b) bulk Pt structure at optimal lattice constants; (c) $\mathrm{Pt}_{104}$ on alumina substrate; (d) $\mathrm{Pt}_{36}$ on alumina substrate. Dashed lines indicate the peak locations for the $1^{\text {st }}, 3^{\text {rd }}$ and $7^{\text {th }}$ shells.

Molecular dynamics simulations based on empirical interatomic potentials were used to gain further insights in the structures of supported Pt nanoparticles, and to provide additional evidence on the Pt-Pt bond contractions of supported Pt nanoparticles. The simulated PDFs, G(r), for Pt-bulk and $\mathrm{Pt}_{104}$ and $\mathrm{Pt}_{36}$ on alumina substrates are shown in Figure 6(a), and the corresponding molecular structures of Pt bulk, $\mathrm{Pt}_{104}(\mathrm{~d} \approx 1.5 \mathrm{~nm})$ and $\mathrm{Pt}_{36}(\mathrm{~d} \approx 1 \mathrm{~nm})$ are illustrated in Figure 6(b-d) respectively. For Pt bulk, the respective Pt-Pt distances for the main peaks at the $1^{\text {st }}$, $3^{\text {rd }}$ and $7^{\text {th }}$ shell are $2.79 \AA, 4.82 \AA$, and $7.37 \AA$ (as labeled in Figure 6). For equilibrated $\mathrm{Pt}_{104}$ and $\mathrm{Pt}_{36}$, the $\mathrm{Pt}$ atoms organized themselves into island with each layer arranged based on the fcc ABC-type stacking, resembling that of the Pt bulk. All the peak locations in G(r) corresponding to their respective $1^{\text {st }}, 3^{\text {rd }}$ and $7^{\text {th }}$ shells move to the left relative to the peaks of $\mathrm{Pt}$ bulk, indicating $\mathrm{Pt}-\mathrm{Pt}$ bond contraction. The Pt-Pt bond distance for each shell follows the order of $\mathrm{Pt}_{36}<\mathrm{Pt}_{104}<\mathrm{Pt}$ bulk. The peak locations of the $\mathrm{Pt}_{104}$ cluster show good numerical agreement with the shell distances for $1 \mathrm{c} \mathrm{Pt} / \mathrm{Al}_{2} \mathrm{O}_{3}$ in $\mathrm{He}$ condition in Table $\mathrm{S}$.

The structures of free $\mathrm{Pt}_{104}$ and $\mathrm{Pt}_{36}$ clusters (without support) were also considered using the Sutton-Chen potential (see Figure $\mathrm{S}_{4}$ in Supporting Information). It can be seen that the contraction of the nearest neighbor $\left(1^{\text {st }}\right.$ shell) are actually comparable between the particles of the same size, e.g. $1^{\text {st }}$ shell Pt-Pt distance of $2.65 \AA$ versus 2.66 $\AA$ for $\mathrm{Pt}_{36}$, and ${ }^{\text {st }}$ shell Pt-Pt distance of $2.70 \AA$ versus 2.70 $\AA$ for $\mathrm{Pt}_{104}$. What distinguishes the free and supported
Pt particles are their geometries, without support the Pt atoms in the cluster are more disorderly arranged, as reflected in the PDFs with less pronounced peak features and more severe Pt-Pt bond contractions especially in the outer shells ( $3^{\text {rd }}$ and $7^{\text {th }}$ shells). It is also obvious that on the substrate the $\mathrm{Pt}_{36}$ cluster shows a flatter geometry (with only two atomic layers) compared to $\mathrm{Pt}_{104}$ (as shown in Figure $\mathrm{S}_{5}$ ). This indicates that the $3 \mathrm{D}$ cluster structures may become thermodynamically more favorable with the increase of cluster size, where smaller clusters show tendency to maximize the interactions with the substrate. In general, the gas phase clusters are more spherical than the supported clusters, although the supported clusters also become more spherical as the particle size increases.

Table 2. $\mathrm{L}_{3}$ EXAFS fits of Pt catalysts at RT with and without adsorbed $\mathrm{CO}$ or $\mathrm{H}_{2}{ }^{a}$

\begin{tabular}{|c|c|c|c|c|c|}
\hline & Adsorbed gas & $\mathrm{CN}_{\mathrm{Pt}-\mathrm{Pt}}$ & $\begin{array}{r}\mathrm{R} \\
(\AA)\end{array}$ & $\begin{array}{r}\mathrm{DW} \\
\left(\mathrm{x} \quad 10^{3}\right)\end{array}$ & $\begin{array}{r}E_{o} \\
(\mathrm{eV})\end{array}$ \\
\hline Pt foil & None (in $\mathrm{He}$ ) & 12 & $\mathbf{2 . 7 7}$ & 0.0 & 0.0 \\
\hline \multirow[t]{3}{*}{ 1c Pt } & None (in $\mathrm{He}$ ) & $5 \cdot 9$ & 2.69 & 2.0 & -1.6 \\
\hline & $\mathrm{H}_{2}$ & 6.0 & 2.74 & 1.0 & -2.3 \\
\hline & $\mathrm{CO}$ & 6.0 & 2.76 & 1.0 & -1.2 \\
\hline \multirow[t]{3}{*}{ 3c Pt } & None (in $\mathrm{He}$ ) & 8.7 & 2.73 & 1.0 & -0.1 \\
\hline & $\mathrm{H}_{2}$ & 8.7 & 2.76 & 0.5 & -0.8 \\
\hline & $\mathrm{CO}$ & 8.5 & 2.76 & 1.0 & -1.3 \\
\hline \multirow[t]{3}{*}{$5 \mathrm{c} \mathrm{Pt}$} & None (in $\mathrm{He}$ ) & 10.0 & 2.74 & 0.5 & 0.2 \\
\hline & $\mathrm{H}_{2}$ & 10.2 & 2.76 & 0.5 & -0.8 \\
\hline & $\mathrm{CO}$ & 9.8 & 2.76 & 0.5 & 0.8 \\
\hline
\end{tabular}

${ }^{\mathrm{a}} \mathrm{CN}$ is coordination numbers with error $\pm 10 \%$. $\mathrm{R}$ is bond distance with error $\pm 0.02 \AA$. DWF is Debye-Waller factor. Eo is energy shift. A two-shell model fit of the $\mathrm{k}^{2}$ weighted EXAFS data was obtained between $\mathrm{k}=2.9-11.7$ $\AA^{-1}$ and $\mathrm{r}=1.3-2.8 \AA$.

To further explore the effects of adsorbates, we conducted in situ XAS measurement at the Pt $\mathrm{L}_{3}$ edge under the same conditions used for the in situ PDF experiments. The bond distances extracted from the XAS measurements were slightly smaller than those obtained from the PDF measurements. This phenomenon has been ascribed to anharmonic vibration of the surface atoms in the small nanoparticles at room temperature. ${ }^{16}$ However, the contraction and relaxation of the Pt bond distances determined by fitting the EXAFS data were very similar to those of the PDF measurements (Table 2 and Figure S6). The bond distance for the $1 \mathrm{~nm}$ Pt-in-He was 2.69 $\AA$. With the adsorption of $\mathrm{H}_{2}$ and $\mathrm{CO}$, the bond distance relaxed to 2.74 and $2.76 \AA$, respectively. Similar trends were observed for the 2-3 $\mathrm{nm}$ Pt nanoparticles but the magnitude of the changes was smaller.

Changes in the electronic structure of small Pt nanoparticles caused by adsorbates may in turn change the $\mathrm{Pt}$ lattice parameters. XANES of the $\mathrm{Pt} \mathrm{L}_{3}$ edge represents a $2 \mathrm{p} \rightarrow 5^{\mathrm{d}}$ transition. As observed in previous studies, adsorption of $\mathrm{H}_{2}$ and $\mathrm{CO}$ results in changes in the shape of 
the $\mathrm{Pt} \mathrm{L}_{3}$ XANES spectra. ${ }^{15}, 45$ Figure 7 shows the $\mathrm{Pt} \mathrm{L}_{3}$ edge for $1-3 \mathrm{~nm} \mathrm{Pt} / \mathrm{Al}_{2} \mathrm{O}_{3}$ with adsorbed $\mathrm{H}_{2}$ and $\mathrm{CO}$. The $\mathrm{L}_{3}$ edge shifts to higher energy and the peaks broaden with adsorbed $\mathrm{H}_{2}$ and $\mathrm{CO}$. These changes are most significant for the smallest Pt particles. The $\triangle$ XANES (XANES of the Pt nanoparticles with the adsorbate minus that in $\mathrm{He})$ has a negative peak at the edge $(\sim 11.564 \mathrm{keV})$ and a positive peak beyond the edge. The area of the positive peaks is suggested proportional to the $\mathrm{H} / \mathrm{Pt}$ or $\mathrm{CO} / \mathrm{Pt}$ ratio, ${ }^{47-48}$ which we ascribe to differences in the Pt particle size and dispersion. Specifically, smaller Pt nanoparticles have higher $\mathrm{H} / \mathrm{Pt}$ or $\mathrm{CO} / \mathrm{Pt}$ ratio under the same conditions because they have a higher percentage of surface atoms. The higher $\mathrm{H} / \mathrm{Pt}$ and $\mathrm{CO} / \mathrm{Pt}$ ratio can cause a larger change in the electronic structure of Pt nanoparticles which reflects as a larger $\triangle$ XANES spectrum.

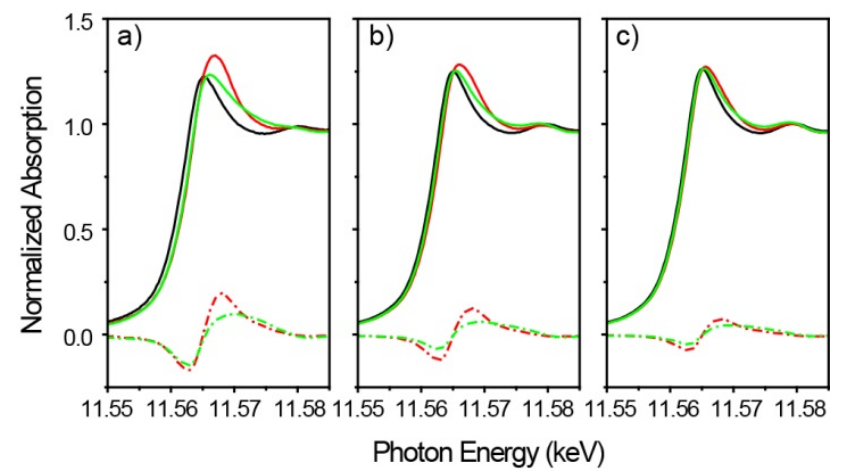

Figure 7. Normalized $\mathrm{Pt} \mathrm{L}_{3}$ XANES and $\triangle \mathrm{XANES}$ of (a) ic $\mathrm{Pt} / \mathrm{Al}_{2} \mathrm{O}_{3}$, (b) $3 \mathrm{c} \mathrm{Pt} / \mathrm{Al}_{2} \mathrm{O}_{3}$, and (c) $5 \mathrm{c} \mathrm{Pt} / \mathrm{Al}_{2} \mathrm{O}_{3}$. Green in $\mathrm{H}_{2}$. Red in CO. Black in He. Solid line $\mathrm{L}_{3}$ XANES. Dash Dot line $\mathrm{L}_{3} \Delta \mathrm{XANES}$ with respect to Pt in He.

Lattice contraction of very small particles has been attributed to changes in the hybridization of metal bonds at the surface that minimize the under-coordination of the surface atoms. ${ }^{45}$ Consequently, the adsorption of $\mathrm{H}_{2}$ and $\mathrm{CO}$ relaxes this lattice contraction in 1-3 $\mathrm{nm}$ Pt nanoparticles due to rehybridization of the metal orbitals. ${ }^{15}$ Our PDF and XAS data suggest the rehybridization caused by $\mathrm{H}_{2}$ and $\mathrm{CO}$ are different, and this finding is consistent with previous DFT calculations. ${ }^{49}$ In PDF measurements, the adsorption of $\mathrm{CO}$ on 1-3 nm Pt nanoparticles would lead to a longer Pt-Pt bond distance and less crystallinity compared to $\mathrm{H}_{2}$ adsorption. In the XANES and $\triangle$ XANES measurements, the changes in $\mathrm{L}_{3}$ edge are more significant when $\mathrm{CO}$ was adsorbed on $\mathrm{Pt}$ as compared to $\mathrm{H}_{2}$. The difference in Pt-adsorbate bonding hybridization can be used to explain the PDF data. In the case of $\mathrm{CO}$ adsorption, it was suggested the hybridization of d-orbitals is involved in back donation to the $\mathrm{CO} \pi$-bond. ${ }^{15}$ In contrast, when hydrogen adsorbs on Pt, Pt-H anti-bonding states are formed with s-d coupling to stabilize the metal cluster $\mathrm{d}$ bonding state. The adsorption of $\mathrm{H}_{2}$ produces a similar, but smaller effect than that with adsorbed $\mathrm{CO}$ in agreement with the previous reports.

\section{CONLUSION}

In conclusion, for 1-3 nm Pt nanoparticles supported over $\mathrm{Al}_{2} \mathrm{O}_{3}$, we have observed changes in the Pt lattice parameters upon adsorption of $\mathrm{CO}$ and $\mathrm{H}_{2}$. In situ PDF measurements showed that the Pt-Pt bond distance contracts by $\sim 1.4 \%$ at the surface of $\sim 1 \mathrm{~nm}$ Pt-in-He nanoparticles. The 2-3 nm Pt nanoparticles showed similar but smaller changes due to the lower fraction of under coordinated Pt surface atoms in larger Pt particles. The adsorption of $\mathrm{H}_{2}$ and $\mathrm{CO}$ at room temperature relaxed Pt-Pt bond contraction to a value near that of bulk fcc Pt. Similar phenomena are confirmed by the in situ XAS study under the same conditions. The adsorption of $\mathrm{H}_{2} \mathrm{im}-$ proves the crystallinity of small Pt nanoparticles. However, with the adsorbed CO, $d$-PDF suggested a more disordered fcc structure for 1-3 nm Pt nanoparticles than the Pt-in-He nanoparticles. This can be explained by the electron back donation from Pt nanoparticles to the $\mathrm{CO}$, leading to higher degree of rehybridization of the metal orbitals in Pt-adsorbates system. These findings will help us to understand adsorbate-induced structural and chemical changes in sub-3 nanometer Pt catalysts and be useful for improving catalytic activity.

\section{ASSOCIATED CONTENT}

\section{Supporting Information}

Additional PDFs fittings, EXAFS spectra and results of MD simulations. This material is available free of charge via the Internet at http://pubs.acs.org.

\section{AUTHOR INFORMATION}

\section{Corresponding Author}

* Phone: 1-630-252-3520, jelam@anl.gov

\section{Author Contributions}

The manuscript was written through contributions of all authors. All authors have given approval to the final version of the manuscript. $¥$ These authors contributed equally.

\section{Notes}

The authors declare no competing financial interests.

\section{ACKNOWLEDGMENT}

This material is based upon work supported as part of the Institute for Atom-efficient Chemical Transformations (IACT), an Energy Frontier Research Center funded by the U.S. Department of Energy, Office of Science, Office of Basic Energy Sciences. Use of the Advanced Photon Source was supported by the U. S. Department of Energy, Office of Science, Office of Basic Energy Sciences, under Contract No. DE-ACo2-o6CH11357. MRCAT operations are supported by the Department of Energy and the MRCAT member institutions. This research was carried out at the Center for Functional Nanomaterials, Brookhaven National Laboratory, which is supported by the US Department of Energy, Office of Basic Energy Sciences, under Contract No. DE-ACo298CH1o886. Y.L. gratefully acknowledges the start-up support by the University of Alabama in Huntsville. B. L. also thanks the start-up support by the Kansas State University. 
We acknowledge grants of computer time at the Argonne Laboratory Computing Resource Center (LCRC), and the National Energy Research Scientific Computing Center (NERSC).

\section{REFERENCES}

(1) Haruta, M., Catal. Today 1997, 36 (1), 153-166.

(2) Argo, A. M.; Odzak, J. F.; Gates, B. C., J. Am. Chem. Soc. 2003, 125 (23), 7107-7115.

(3) Guzman, J.; Carrettin, S.; Fierro-Gonzalez, J. C.; Hao, Y. L.; Gates, B. C.; Corma, A., Angew. Chem., Int. Ed. 2005, 44 (30), 47784781.

(4) Lei, Y.; Mehmood, F.; Lee, S.; Greeley, J.; Lee, B.; Seifert, S.; Winans, R. E.; Elam, J. W.; Meyer, R. J.; Redfern, P. C.; Teschner, D.; Schlogl, R.; Pellin, M. J.; Curtiss, L. A.; Vajda, S., Science 2010, 328 (5975), 224-228.

(5) Hagen, J., Industrial Catalysis. Wiley-VCH: Mannheim, 2006.

(6) Bartholomew, C. H.; Farrauto, R. J., Fundamentals of Industrial Catalytic Processes. 2nd ed.; Wiley-AIChE: New York, 2005.

(7) Tsung, C. K.; Kuhn, J. N.; Huang, W. Y.; Aliaga, C.; Hung, L. I.; Somorjai, G. A.; Yang, P. D., J. Am. Chem. Soc. 20o9, 131 (16), 5816-5822.

(8) Lennard-Jones, J. E.; Dent, B. M., Proc. R. Soc. London, A 1928, 121, 247-259.

(9) Bunn, C. W., Proc. Phys. Soc. 1935, 47 (5), 835-842.

(10) Finch, G. I.; Fordham, S., Proc. Phys. Soc. 1936, 48 (1), 8594.

(11) Boswell, F. W. C., Proc. Phys. Soc. A 1951, 64 (5), 465-476.

(12) Berry, C. R., Phys. Rev. 1952, 88 (3), 596-599.

(13) Apai, G.; Hamilton, J. F.; Stohr, J.; Thompson, A., Phys. Rev. Lett. 1979, 43 (2), 165-169.

(14) Miller, J. T.; Kropf, A. J.; Zha, Y.; Regalbuto, J. R.; Delannoy, L.; Louis, C.; Bus, E.; van Bokhoven, J. A., J. Catal. 20o6, 240 (2), 222-234.

(15) Lei, Y.; Jelic, J.; Nitsche, L. C.; Meyer, R.; Miller, J. T., Top. Catal. 2011, 54, 334-348.

(16) Hansen, L. B.; Stoltze, P.; Norskov, J. K.; Clausen, B. S.; Niemann, W., Phys. Rev. Lett. 1990, 64 (26), 3155-3158.

(17) Bus, E.; Miller, J. T.; Kropf, A. J.; Prins, R.; van Bokhoven, J. A., Phys. Chem. Chem. Phys. 20o6, 8 (27), 3248-3258.

(18) Billinge, S. J. L.; Levin, I., Science 2007, 316 (5824), 561-565.

(19) Proffen, T.; Billinge, S. J. L.; Egami, T.; Louca, D., Z. Kristallogr. 2003, 218 (2), 132-143.

(20) Newton, M. A.; Chapman, K. W.; Thompsett, D.; Chupas, P. J., J. Am. Chem. Soc. 2012, 134 (11), 5036-5039.

(21) Zhao, H. Y.; Nenoff, T. M.; Jennings, G.; Chupas, P. J.; Chapman, K. W., J. Phys. Chem. Lett. 2011, 2 (21), 2742-2746.

(22) Elam, J. W.; Groner, M. D.; George, S. M., Rev. Sci. Instrum. 2002, 73 (8), 2981-2987.

(23) Chupas, P. J.; Ciraolo, M. F.; Hanson, J. C.; Grey, C. P., J. Am. Chem. Soc. 2001, 123 (8), 1694-1702.

(24) Hammersley, A. P.; Svensson, S. O.; Hanfland, M.; Fitch, A. N.; Hausermann, D., High Pressure Res. 1996, 14 (4-6), 235-248.

(25) Farrow, C. L.; Juhas, P.; Liu, J. W.; Bryndin, D.; Bozin, E. S.; Bloch, J.; Proffen, T.; Billinge, S. J. L., J. Phys.: Condens. Matter 2007, 19 (33).

(26) Ilavsky, J.; Jemian, P. R., J. Appl. Crystallogr. 2009, 42, 347353.

(27) Smith, W.; Forester, T. R., Journal of Molecular Graphics 1996, 14 (3), 136-141.

(28) Matsui, M., Mineralogical Magazine 1994, 58A, 571-572.

(29) Rafiitabar, H.; Sutton, A. P., Philosophical Magazine Letters 1991, 63 (4), 217-224.

(30) Sutton, A. P.; Chen, J., Philosophical Magazine Letters 1990, 61 (3), 139-146.

(31) Levine, S. M.; Garofalini, S. H., Surf. Sci. 1986, 167 (1), 198206.

(32) Athanasopoulos, D. C.; Garofalini, S. H., J. Chem. Phys. 1992, 97, 3775-3780.
(33) King, J. S.; Wittstock, A.; Biener, J.; Kucheyev, S. O.; Wang, Y. M.; Baumann, T. F.; Giri, S. K.; Hamza, A. V.; Baeumer, M.; Bent, S. F., Nano Lett. 2008, 8 (8), 2405-2409.

(34) Dasgupta, N. P.; Liu, C.; Andrews, S.; Prinz, F. B.; Yang, P. D., Journal of the Americal Chemical Society 2013, 135, 12932-12935.

(35) Setthapun, W.; Williams, W. D.; Kim, S. M.; Feng, H.; Elam, J. W.; Rabuffetti, F. A.; Poeppelmeier, K. R.; Stair, P. C.; Stach, E. A.; Ribeiro, F. H.; Miller, J. T.; Marshall, C. L., J. Phys. Chem. C 2010, 114 (21), 9758-9771.

(36) Lei, Y.; Liu, B.; Lu, J. L.; Lobo-Lapidus, R. J.; Wu, T. P.; Feng, H.; Xia, X. X.; Mane, A. U.; Libera, J. A.; Greeley, J. P.; Miller, J. T.; Elam, J. W., Chem. Mater. 2012, 24 (18), 3525-3533.

(37) Aaltonen, T.; Ritala, M.; Tung, Y. L.; Chi, Y.; Arstila, K.; Meinander, K.; Leskela, M., J. Mater. Res. 2004, 19 (11), 3353-3358.

(38) Chupas, P. J.; Chapman, K. W.; Jennings, G.; Lee, P. L.; Grey, C. P., J. Am. Chem. Soc. 2007, 129 (45), 13822-13824.

(39) Chapman, K. W.; Chupas, P. J.; Kepert, C. J., J. Am. Chem. Soc. 2005, 127 (32), 11232-11233.

(40) Chupas, P. J.; Chapman, K. W.; Chen, H. L.; Grey, C. P., Catal. Today 2009, 145 (3-4), 213-219.

(41) Somorjai, G. A.; Park, J. Y., Angew. Chem., Int. Ed. 20o8, 47 (48), 9212-9228.

(42) Martinez-Inesta, M. A. M.; Lobo, R. F., J. Phys. Chem. C 2007, 111 (24), 8573-8579.

(43) Egami, T.; Billinge, S. J. L., Underneath the Bragg Peaks : Structural Analysis of Complex Materials 1st ed.; Pergamon: 2003.

(44) Li, L.; Wang, L. L.; Johnson, D. D.; Zhang, Z. F.; Sanchez, S. I.; Kang, J. H.; Nuzzo, R. G.; Wang, Q.; Frenkel, A. I.; Li, J.; Ciston, J.; Stach, E. A.; Yang, J. C., Journal of the Americal Chemical Society 2013, 135, 13062-13072.

(45) Bus, E.; van Bokhoven, J. A., J. Phys. Chem. C 2007, 111 (27), 9761-9768.

(46) Ramallo-Lopez, J. M.; Santori, G. F.; Giovanetti, L.; Casella, M. L.; Ferretti, O. A.; Requejo, F. G., J. Phys. Chem. B 2003, 107 (41), 11441-11451.

(47) Kubota, T.; Asakura, K.; Ichikuni, N.; Iwasawa, Y., Chem. Phys. Lett. 1996, 256 (4-5), 445-448.

(48) Reifsnyder, S. N.; Otten, M. M.; Sayers, D. E.; Lamb, H. H., J. Phys. Chem. B 1997, 101 (25), 4972-4977.

(49) Schweitzer, N.; Xin, H. L.; Nikolla, E.; Miller, J. T.; Linic, S., Top. Catal. 2010, 53 (5-6), 348-356. 
TOC figure

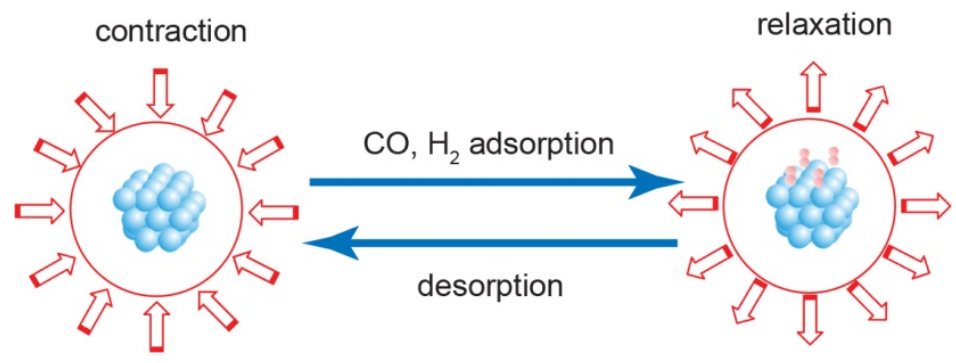

